\title{
Remember Not To Die: Young Girls and Video Games
}

\section{Valerie Walkerdine}

\author{
'Remember not to die. All you have to do is not \\ die and you'll win. How easy is that?'
}

I $\mathrm{n}$ this paper about girls and video games I shall criticise the notion that a central issue for girls is the kind of games available to them. Instead, I argue that many games offer one site for the production of contemporary masculinity (see Walkerdine 2002). If my analysis has anything to offer, what it demonstrates is that the task for boys and for girls when playing games is different in each case. If we think about this in terms of Foucault's ideas (Foucault 1986) about self management techniques, then the task of working to become masculine is certainly not easy for boys but perhaps more straightforward in terms of self-management practices. For girls, on the other hand, if the performance of masculinity is what is produced in relation to game play, their self management task is so much more complex. That is, they have to pursue the demands of contemporary femininity which blend together traditional masculinity and femininity. Trying to do this while playing games is a very complex and difficult task.

With this theoretical framework in mind I want to address some central issues of masculinity and then go on to discuss how girls play games. I shall interpret their play through a framework which assumes that they are managing contradictory positions of masculinity and femininity. The data for this paper comes from an Australian Research Council funded study of children in Sydney aged between 8 and 11 playing video games, together with interviews with the children and their parents.

\section{Hollywood narratives of masculinity}

Successful completion of many video games involves triumph over a series of obstacles. The character played by the player faces many challenges and is frequently in danger of being killed. What is very striking about the games narratives and plot structure is that they resemble the struggles for the achievement of masculinity described so clearly in 1970s film theory analyses of the classic Hollywood Westerns (cf. Neale 1983). In this analysis, the hero's attempt to recover from a number of defeats and to finally triumph is the psychic and cultural work of masculinity.
My argument, that the narrative structure of many popular video games closely resembles that of Westerns, gives us a clue to the way that intertextuality works to inscribe the game player inside narratives through which masculinity is accomplished. The video games implicitly refer not only to the classic Western but also the Hollywood action-movie genre that follows from them. What makes video games pleasurable is the achievement of masculinity despite (or because of) the many possible pitfalls along the way. Of course, the game player is not a film spectator, so how do we understand the inscription of the player into the game itself? The player has to manipulate a character, and in some games, choose that character who possesses certain particular characteristics such as special moves, which are vital to progress through the game. As the title of Stephen Poole's book, Trigger happy (2000) suggests, shooting is absolutely central to many games; that is, while the player controls the game console and manipulates the joy stick, it is the character who is actually progressing through the game. Stephen Poole says 'videogames are fun. But what kind of fun is it?'(p.28). For Poole, the answer lies in understanding the aesthetics of games and the way in which their particular aesthetic provides signs which inscribe the player. I would add that the pleasure in the aesthetic is about masculinity. As Poole himself says: '...the appeal of this kind of epic videogame is to be "an action-movie hero"'(p.114). He therefore concedes that the pleasure of games, as in action movies, is the production of an active and heroic masculinity. It is the achievement of that heroism which is pleasurable and makes games fun. If this is the case, the issue of gender in relation to video games becomes something quite other than whether games contain male or female characters, which is a fairly standard position in the literature on gender and video games (cf. Cassell \& Jenkins 1998).

If the achievement of a certain kind of masculinity is what the games deliver, then the struggles for its achievement are what produce the pleasure of the game. In addition, video games also present a new masculinity, a playful masculinity in which some characters kill others in a vicarious game which mimics and is also a pastiche of a Western. More than this, to be good at games one must develop certain skills, certain kinds of thinking, what Poole calls 'reflexes, speedy pattern recognition, spatial imagination' (p.56). 
The development of skill and strategy in game-playing is what produces the action-hero. Thus, the most skilled players perform action masculinity (killing enemies that stand in their way, saving the world and the like) from the safety of their lounge rooms or bedrooms. Because this demands interactive skills and not just an imaginary identification with a hero in a comic, book or film, it has to be achieved by action on the part of the player. This action is not physical action but skill in making moves, rational strategy, cognition. In fact, the identification with the hero (as in print or film media) will not alone produce success. Wanting to be that hero requires work, constant hard work, the work of continual practice, as many of the children in the study make clear. And of course, as many girls say, they are not so interested in that kind of work because its end point, action-heroic masculinity, is not the work they have to achieve. The work of femininity is different.

But because the game-played action-hero is achieved in the home, what is delivered to the successful player is not brawn but brains - not a body ready for fighting, or reflexes quick on the draw, but a different kind of finger on a different kind of trigger, as Stephen Poole's title indicates. Thus it is the rational subject, the subject of calculating mastery, who is delivered by the games - the hero who is quick on the joystick rather than quick on the draw. Indeed, such a hero is fit for the post-industrial world in which a more traditional masculinity of the body is only evoked and re-membered within a situation where the mind is all and the evil opponent is only a screen memory.

However, the production of the successful player is not simply about the development of certain kinds of cognitive skills, because we cannot understand those skills outside the production of a particular form of the subject. That subject, the successful game player as rational masculine subject, is created out of a number of demands and practices, all of which add up to a great deal of hard work to form the masculine, games simply being one site of its production. The learning of successful moves and strategies is simply part of that creation. It does not make sense to understand the psychology of the skill acquisition outside the production of this subject. The desire to learn the skills, the friendships which support it, the magazines consumed, identifications, defences, and the cultural and social practices which produce the successful game player are as much about skills as they are about any cognitive processes. In any event, the moves in any game are made by the character, not the player as himself. Thus, the games demand a kind of ventriloquism, in which the player makes the character perform in a certain way, but it is a more complex partnership in which the characteristics of the character - their special moves and so on have to be harnessed in relation to the obstacles and challenges provided by the game world itself. Thus, the choice of character is absolutely central to good performance.

In this analysis, violence is not an effect of video games, nor are video games a cathartic space in which violent emotions can be safely expressed. Rather, the self-management of action and violence in the Foucauldian sense is a key task for contemporary masculinity. It is the self-management of the appropriateness of displays of action and violence in different forms and within different practices which is so difficult. Video games therefore provide one site in which self-management can be practised, in that the violence is vicarious and yet requires the use of rational techniques and strategies.

\section{Managing femininity}

In the light of this argument, I want to explore some central issues about girls' video game play. I begin with an observation made early on in the Sydney project by one of the researchers. She felt very disappointed when she was watching the girls play - she felt that they played in a different way from the boys, that is, more sociably, with game playing as an accompaniment to other activities, such as chatting, and that they didn't play to win or with the competitive edge of the boys. She was upset by this because as a girl at school she had been good at mathematics, which had singled her out, and she felt disappointed that the girls were not displaying the technological enthusiasm she would have liked them to display. We subsequently analysed the way the girls played very carefully and felt that there was no basis for suggesting in any simple terms that the girls played differently from the boys. However, the researcher was not deluded. What she had picked up was a difference in orientation to games. This difference has been the subject of a growing body of literature (see Cassell \& Jenkins 1998 for a review) about girls and video and computer games. 


\section{The difficult question is how much one might want to intervene in the particular work of gender construction being done by a game and, if one does, how that can best be achieved.}

Much of this literature looks at a number of factors to explain girls' lower participation in games.

I want to propose that if games are one site for the production and management of contemporary masculinity, the task for girls playing video games is a complex one. By comparison, in the mathematics classroom it was not a simple matter of girls behaving more like boys - breaking rules and so on — in order to be recognised as mathematical thinkers. Far from it. Examples from that research (Walkerdine 1998) demonstrated that it was certainly not a simple matter of girls behaving or performing differently. The same performance which teachers praised in boys they commented on pejoratively in girls. I am suggesting therefore that it is not simply a case of making video games 'girl friendly', nor in any simple sense that girls don't like or are no good at video games. Rather, I want to raise the difficulties of the management of contemporary femininity, which demands qualities traditionally ascribed to masculinity — action, rationality, work and so forth - while girls and women must also display qualities traditionally ascribed to femininity in order to signify their femininity. This is a complex and some might say impossible task for girls and women. In relation to video games, it places them in a contradictory position. If video games are part of a set of technologies and practices for the production and management of contemporary masculinity, then in order to succeed in games girls have to manage themselves as both masculine and feminine. They have a more complex self-management task than boys. Boys have to try to win to embody masculinity but girls wanting to win risk losing their designation as feminine by coming too far onto the side of masculinity. Thus their task of self management is harder - they have to perform masculinity as well as femininity.

In this paper I want to explore these issues by referring to data collected for an Australian Research Council study I undertook in Sydney. In this study equal numbers of boys and girls aged between 8 and 11 played video games in two after-school clubs in inner and outer Western Sydney; the children and their parents were interviewed in their homes. My analysis uses the interview transcripts and transcribed video tapes from the club sessions, where children played in mixed and single sex groups. I want to explore the complex ways in which some girls in the study managed the contradictory positionings outlined above. It should be said at the outset that there were girls who were very keen on winning - it was very far from the case that girls didn't want to win - but it was the case that no girl was as competent or indeed interested as a player as the most skilled boys.

\section{The self-presentation of girls as disavowing violence and liking only cuteness}

Of course we all 'know' that women like cute and fluffy animals as well as babies and small children. On first glance, this liking for soft and cuddly things speaks of nonviolence, of softness and kindness. It may however serve another purpose, to divert attention away from power and aggression: we see cuddly kittens, not dangerous tigers. Or perhaps being cute and cuddly is a way of tolerating oppression and powerlessness and making it into a virtue. Whatever the reason, many girls in the study chose cute and cuddly characters as their favourites in the games which they played in the club. These were the top-rated games for their age-group.

The five favourite characters chosen by the girls are Kirby, Donkey Kong, Pikachu ('he's the cute and cuddly one'), Princess Peach and Angelica. As we can see, it is not the case that girls always choose female characters but their top characters, if not female, are of the cute and cuddly kind. Both girls and boys talk about female characters as having less power. Princess Peach is the most obvious example of this. There is some debate amongst the children about whether she is a poor character, but generally it is assumed that if the girls pick her they are not going to win because she has poor powers. However, this does not stop some girls picking her because they like certain of her qualities, usually the fact that she is pretty and a princess. Thus, the girls who choose her are condemned to doing poorly in the game. There is an interesting difference between those girls who would rather choose her for her appearance and those who like being active.

Some girls also talk about desirable male characters as 'cuddly' or 'cute'. For example, Bella dreams of Pikachu as a pet: 'Whenever he needs sleep or something I'd be really gentle with him.' The girls operate as though they will be more able to cope with the male characters if these are 
brought down to size, rendered less macho. This positions the girls very clearly as mothering caring women who can gain power by looking after an emasculated cuddly male character. This suggests that this position is one in which the cuddly male character is rendered powerless and the girl powerful. It is a good way to manage the contradiction of femininity and masculinity in that it gives the girl a position of power, but it is, of course, very restrictive. It does not seem to allow her to embody a winning character nor does it allow her to be 'aggressive'. In this scenario, there is no aggression at all — neither for males nor females. So, rendering the male character cuddly certainly cuts down the possibility of the girl as object of violence but at a very high price.

The characters that some girls favour seem to be to be versions of a classic femme fatale. The version of 'cute with a poison sting' (Molly's choice of Bilbasaur and Licka Tongue seems to sum it all up). The femme fatale of course exudes an active and passionate sexuality, but within classic melodrama or thrillers she is often evil, and while she is allowed to be active and powerful (gun toting, for example) she is never allowed to survive. If such characters in these games were available to girls (and boys), it would be very powerful for girls. Miriam likes 'a cute little person with a dress on, a crown, blondie hair, nice shoes and a princess'. She is too scared to play a boy character and she doesn't like them - 'big, huge moustache', 'big fat bully'. I am led to wonder who she is describing. However, she likes Techno 3 fighting girls, wrestling girls who are 'pretty and scary'. So, an acceptable position seems to be the double positioning as cute and powerful. Again, this is a useful way for a girl to resolve contradictions of femininity and masculinity. It is my guess that it would be much harder for many girls to like a [female?] character who had the metaphorical 'poison tongue' but who was not cute, as this might mean crossing too far onto the side of masculinity. This relates to their favourite characters from television: the sisters from Charmed, Power Puff girls, Zena, Sabrina, all of whom could be described as possessing those dual characteristics.

I am suggesting therefore that choosing cute and cuddly characters or femmes fatales are two ways of finding a position which attempts to resolve the contradiction between femininity and masculinity which the girls must hold in some way. In the next section, I discuss the different ways in which girls cope with attempting to perform masculinity while also performing femininity — that is, how they deal with these contradictions within game play itself.

\section{Rosie and Bella}

This analysis is based upon a detailed case study of two girls, Rosie and Bella, who both in their different ways exemplify performance which attempts to perform masculinity while maintaining a performance of femininity. First, though stating the obvious, it is important to recognise the girls as situated in a binary construction of gender. They are situated as female subjects in contexts where femininity carries certain privileged inscriptions as well as some that are required to be disavowed. For example, it is clear from the interviews with both parents and children that boys are associated with violence and fighting and possible negative effects of computer games, but never girls. It is clear from the interview transcripts that girls position themselves as liking cute characters and not liking the fighting in the games, but attention to the videos suggests an excitement and engagement in the activity of killing and competing that is disavowed through the girls' constructions of themselves in the interviews.

At one point in the transcript one of the girls, Rosie, repeatedly asks her play companion, Bella, if she can have a turn. Bella ignores the request until this point:
66. Rosie: If you kill yourself in half the time then you can go to another world ...
67. Bella Yeah, I know, but then it will be game over, then it's your go.
68. Rosie: No.
69. Bella: It is.
70. Rosie: I'll let you have another go.
71. Bella: No, it's all right. I want you to.
72. Rosie: It's just if you don't like this level. But you have to tell me if you don't like this level and you're going to kill yourself, 'cause you can say that any time.
73. Bella: Wow.
74. Rosie: Do you like [....] or something?
75. Bella: No I don't. 


\section{How easily and seductively it can align us with those values by making us want to succeed in the game.}

\author{
76. Rosie: Yes you do. This is your last lap, one \\ before my turn, and then it's my go. \\ 77. Bella: No it,s not. \\ 78. Rosie: Yes it is. \\ 79. Bella: Was only joking. Wow. \\ 80. Rosie: Remember it's not like for the rest of \\ the time it's my go. \\ 81. Bella: I know, but you're probably good at \\ this. \\ 82. Rosie: No I'm not. [giggles] Believe me, Idon't \\ go into this level.
}

In this example Rosie and Bella are engaged in the issue of when Rosie will get a turn. Open conflict or arguing is avoided as they each conduct a series of covert negotiations instigated by Rosie and resisted by Bella. There is nothing that passes as overt power-play as it is conducted in a friendly, non-confrontational manner, despite the complex work spent on positioning themselves as non-contesting subjects whilst actually contesting when Rosie will get a turn. Rosie seems to simultaneously suggest she is not interested in having a turn (deferring to Bella) whilst working hard to ensure that she gets a turn. Rosie reminds Bella that even when she does get a turn 'it's not like for the rest of the time'. Bella, on the other hand, simultaneously suggests she wants Rosie to have another go ('it's alright, I want you to') whilst resisting the possibility of its happening: she is dismissive of Rosie's suggestion for play with 'Yeah, I know, but then it will be game over, then it's your go'. In the face of Rosie's continued attempts to negotiate her turn Bella later positions herself as 'only joking'. When Rosie finally gets her turn she giggles and disavows her competence, thus locating herself in her habitual 'feminine' position of incompetence. Thus the girls' positioning as female subjects necessitates this more passive and covert negotiation of power, especially in terms of a relation of coercion and resistance. This requires Rosie to simultaneously express and disavow her desire to have a turn; it also requires Bella to simultaneously resist whilst appearing not to ('only joking'). This is very interesting in light of teachers' typical comments that boys deal with conflict more openly and honestly than girls - a quick verbal outbreak or a punch and then it's all over and forgotten - and that girls are sly, more mean and hurtful and drag the conflict out. When read as a performance of gender and the imperative for girls to be 'nice', 'friendly' and 'cooperative' it is no wonder that these different patterns in managing conflict emerge. Clearly the work that Rosie and Bella are doing around turn taking is situated in the imperatives of being 'girl'. This necessarily produces the negotiation of contradictory inscriptions: they are required to disavow the desire for control, authority and self-interest whilst simultaneously acting to achieve these things.

This ambivalence is also played out in terms of knowledge and mastery. Rosie routinely takes up a position as 'dumb' although she has greater knowledge and familiarity with the game, while Bella takes up the position of authoritative knower even when she is wrong or does not know. Rosie seems to defer to Bella's position, not in that she does not continue to assert the validity of her knowledge, but in that she does not question or contest Bella's position of authority.

108. Bella: ... I think I'm gonna like this one better. I wanna do this one, The Great Wall of China. 109. Rosie This is not The Great Wall of China. 110. Bella: Well I didn't say it is. Oh no, this is ...

111. Rosie: That's the one where you ...

112. Bella: I know this isn't The Great Wall of China, I know. What happens when you fall in that? Is that water?

And later...

602. Bella: Now look, who's the expert at this: you or me?

603. Rosie: Umm, you.

604. Bella: Thank you. You gave my advice.

605. Rosie: You always were the expert.

Here Rosie concurs with Bella's positioning of herself as the 'expert'. This is not a position open to Rosie as she positions herself as 'dumb' and 'stupid'. Despite Rosie's greater knowledge and familiarity, she is a tentative player who rarely takes risks. (Her wins on another occasion are often a function of conservative play whilst the others take risks and then lose.) She focuses her play on avoiding being killed and often pleads, '[D]on't kill me'. She is the subject upon whom killing is performed. Bella, on the other hand, is the subject who kills. She is a greater risk taker and is often impatient with Rosie's caution and slowness. Bella positions herself positively in relation to mastery and 
authority, despite her lack of knowledge and experience, while Rosie positions herself as hopeless and incompetent, and by implication lacking mastery and authority, despite her comparatively greater knowledge and experience. When Rosie watches Bella play she is helpful, supportive and encouraging, constantly affirming what a good player Bella is. When Bella watches Rosie play she is impatient, derisive and critical. Again, I read this as a reflection of Bella's mobility and ability to take up 'masculine' positions (as she states, she is 'a hard person') and Rosie's more stable location as a 'feminine' subject, one who can be 'helpful' but neither authoritative or masterful. Rosie positions Bella as 'crazy' and Bella positions Rosie as 'lacking', slow, cautious, inept, scared: 'Oh this guy's easy, come on [very impatient and derisive]... You're too scared.' I'd like to stretch a point and propose that 'crazy' is an inscription of the other as 'not girl' or 'boy', and that 'lacking' is an inscription of other as 'not boy' or 'girl'.

125. Bella: Well, that's some.... I dare you to go in that.

126. Rosie: No. I don't want to kill myself. Did anybody notice here that this girl called Bella, I know her? She's really crazy.

And later...

134. Rosie: You're crazy.

135. Bella. What? Fall into that hole. Fall into that

hole. Kill it. Just run, run, run. Do you ever want to get to this castle? Like, yes. Oh no.

136. Rosie: You must hate me sometimes.

137. Bella: No. Just, naar, onlyjoking. I was joking when I said that. You see I'm a hard person. Does the frog kill you?

138. Rosie: No he kisses you. [giggles]

139. Bella: And then you turn into, um, a charming prince.

Still later...

176. Bella: You'renotgoing to. Don'tworry, there's not that much things anyway. Jump. What's wrong with you? If you could...

177. Rosie: 'Cause last time Ijumped over, Inearly died. I need hundreds. Oh, I only got six there.

178. Bella: Yeah, 'cause you had a life, you got a life then. Oh you take your time.
179. Rosie: [laughs] What?

180. Bella: Gee, you take your time. Just run through the gate.

181. Rosie: [giggles] I'm trying.

182. Bella: Ah ah, you're trying?

183. Rosie: Yeah, I'm trying.

184. Bella: [mimics] I'm trying.

185. Rosie: I'm trying. I know I'm trying, I'm scared now. I'm scared.

Rosie frequently describes herself as 'scared'; 'I'm scared', 'I'm so scared', 'I'm scared now', 'this is scary', 'It's too scary for me'. As a player she is preoccupied with dying and being killed and with avoiding this fate. In the following extract 'scared' and 'dumb' are treated as identical states.

197.Rosie: I'm so scared. Is it going to hurt me? 198. Bella: [adopting a patronizing adult voice] No darling.

199. Rosie: Oh, I'm ... [sings] Dah, dumb, dumb.

Dumb ... scared.

Yet as a watcher she explicitly encourages Bella to kill: 'Try and kill that frog', 'Kill the frog. Scootch him. Smooch him. Smooch him', 'Kill him. Kill him'. But she also protests, 'I can't watch. I can't watch'. Thus, when Bella follows her entreaty to kill Rosie hides behind her hands, arms, or turns away, maintaining her position as 'scared' (a position often taken by women when watching violent films?). She thus manages the activity of killing by asking someone else to do it for her when she is the player and encouraging the other to kill when she is observer. Despite the requirement of the game that play proceeds by killing, Rosie resists this by either playing cautiously to protect herself or asking someone else to do the killing for her. The contradiction between this simultaneous disavowal and engagement is masked by the feminised performance of 'scared' and 'hiding'.

Bella, on the other hand, shows no hesitation to position herself as 'killer'. Just as Rosie is preoccupied with being 'scared', Bella is preoccupied with 'killing'; 'I can kill it', 'Yeah I killed it'. She never talks about herself as in danger, as scared or as likely to be killed. It is important to remember that within the game killing is associated with mastery and winning and so Bella often talks about 
which levels are hardest and about her success at getting to another level. Bella is advantaged by Rosie's 'scaredness' and reluctance to kill. In performing the killing for Rosie, Bella gets control of the game and the turn reverts to her even when it is not her turn. After one such episode Bella is careful to remind Rosie that even though Bella is playing she is playing Rosie's turn and that when the game is over it will still legitimately be Bella's turn. In this way the issue of turn taking continues to be an ongoing if not always overt struggle.

\section{Bella: I'm probably gonna have your go, my go, then. I'm probably going to have both of them you're so scared. \\ 808. Rosie: Yeah I know. I'm scared of everything. \\ I'm scared. \\ 809. Bella: Why would you be scared? This is easy. \\ 810. Rosie: Rrrrrrrrrrr. Kill, kill, kill. Run, run, run. Kill. Can you try and go over there? Because I, I don't know. \\ 811. Bella: No. \\ 812. Rosie: Ugabuga. Scary. Don't make me go through this again. Oh yeah, I forgot, I'm not doing it. [giggles] Oh, you're going to scare me like that, aren't you Lillypot? Oh, yeah, and the fish are gonna to scare me too. Why's everyone trying to scare me? \\ 813. Bella: I don't know. Probably they hate you. \\ 814. Rosie: Yes. I think that too. It's so amazing isn't it? Such an intelligent girl. Wooga, wooga. Get that thing. Get that thing. Kill the fish. Kill the things. Kill the boxes! [giggle] Kill the boxes. The boxes are so rude to us. \\ 815. Bella: Oh, where am I going? \\ 816. Rosie: Ahh, get them, get them all, get them all, get them all.}

I want to emphasise here the extent to which these exchanges appear to be very friendly. From the videos the girls appear to be mucking around, having fun, using funny voices, joking with each other and getting along very well. The contestation over control is thus invisible - it cannot be seen, and is more easily read on the page in terms of the complex and ongoing negotiation of positions. These positions centre on the issue of power and control and are played out through turn taking. What the girls are negotiating is 'who will take control'. Here control is both literal and an inscription of power. They are engaged in an embodied performance of and with a technology that is manipulated through the 'control' or console. They are playing a game for one player only and must thus take turns. The player has the 'control' and is thus located in the position of power. The ongoing negotiation of who will have a turn is thus also about who will have control. Rosie is mobile between the role of watcher and player, except when it comes to the 'scary killing bits' when she cedes control of the play to Bella. Bella, on the other hand, is a very impatient watcher; she prefers to play and willingly plays Rosie's turn for her. This fascinating construction, 'playing her turn for her', masks the fact that Bella is actually playing and in control. Both girls are aware of this, but the relation of power they have established through Bella's dominance and Rosie's acquiescence successfully keeps the power play covert. In the continuing struggle to get Bella to play level three Rosie flatters her by telling her what a good player she is, at one stage resting her chin on her hand and fluttering her eyelids. Again, this flattery might be read as 'manipulation' through 'feminine wiles'. It also serves to make safe the position that Rosie takes in relation to Bella, assuring her that she (Bella) has more authority. This desire for safety is consistent with the position that Rosie takes up in relation to herself as a game playing subject - cautious, preoccupied with her safety, worried about dying and avoiding the scary bits. This can be read as a thoroughly 'feminine' inscription, and whilst she competes for power from this position she is ultimately acquiescent and silenced.

\section{Playing a four-player game}

In one episode Rosie and Bella play a four-person game with Jo and Gaby. They each have a separate control and are playing separate characters. They stay in the game as long as their character survives. At the end of the game they engage in a perfunctory discussion of who has won and who came second, third and fourth. This position of winning is constructed for them, as the information is displayed on screen at the end of the game. In saying that their discussion is perfunctory I'm not suggesting that they do not want or like to win, though they take quite different attitudes to winning. Rather, winning does not visibly confer 


\section{How different texts in the different media position their readers/users is a fundamental question if one is interested in the textual creation of subjectivity.}

any status on the winner. Status seems already established along other lines and is not affected in any major way by incidences of winning. Rosie, for example, positions herself as a 'dumb' 'loser'. Even though she sometimes wins, often through default or cautious play, she still positions herself as the loser. Clearly, the position she takes in the group is not contingent on her winning, but on her losing or positioning herself as the loser. Jo does not always win, but she has most authority in the group. All negotiations are conducted through her and she sits most centrally and acts most centrally to the play. Wining or losing does not alter the position of authority that Jo assumes. The positions the girls take up are reasonably stable across for the duration of the episode. Jo and Rosie are central in terms of physical position and dominance. They dominate the conversation and the activity. Bella on the outer right is relatively silent and intensely focussed on the play. The bulk of her comments are play related self-talk directed at the on screen characters. Gaby on the outside left says almost nothing and is most animated when she identifies her place at the end of the game. Jo and Rosie are friends and their relationship, and Jo's status as the leader, are firmly established. Thus, though Jo and Rosie dominate the talk, Jo's position as the one with most authority is unchallenged. (As a way of thinking about the positions the girls seem to take up I think of Jo as 'boss', Rosie as 'dumb', Gaby as 'invisible' and Bella as 'silent killer'.) All the girls are engaged in and by the play.

What struck me on first viewing was the position Jo takes up as a game-player. She dominates the group, the space, the game and the noise level. She does the majority of the work in managing the group in terms of the selection of games, characters and so on. ('Alright, you ready?', 'Everyone ready? Are they sure?') She is loud, bossy, takes a lot of physical space, does air-punch type moves of victory, says 'whoo hoo' and other similar calls that's seen to connote power and control. Jo typically says such things as 'Ar.Ar.Ar. Wait for a second.... Fire, fire, fire. Come back, come back, come back. Yes. Oh bugger.' Rosie on the other hand typically says 'Don't hurt me. I'm innocent', often in an affected whisper or an exaggeratedly 'girly' 'loser' voice. Gaby, though mostly silent, is more likely to make observations about her play and herself as player: 'That's me', 'I'm flying' and the like. Bella, like
Jo, is intensely focussed on the game and on the action of the game: 'Kick. Kick, kick, kick. Kick him up. Oh. Come on. Yeah jump. Jump.' Unlike Jo, Bella engages in little social talk directed at the other players or any audience other than herself. When Bella and Jo laugh it is strong and throaty. Rosie, on the other hand, giggles.

I am conscious as I write this that I am employing stereotypes, and gendered ones at that, and this is because I am trying to generate a sense of how the girls seem to position themselves and how I read their positioning. The successful game playing subject is 'masculine' (both in terms of the technology and the action of fighting, killing and wining) and those girls who are most engaged with the games, who are most successful or have the most power in the group, take up what might generally be identified as more masculine positions. Gaby is silent - a feminised position. Rosie is, in her own words, 'dumb', 'a loser', 'an idiot', 'scared' and is prone to giggling and squeamishness ('Don't try and hurt me') and turning away when killing takes place - a feminised position. Jo is in control, loud, authoritative, skilled, knowledgeable and enjoys winning and killing: 'Weeee. Boom. [makes noises and then laughs]', 'I'm just bashing up everything' — a masculinised position. Bella, though less engaged in the social activity and talk of the group, is very focussed on the killing activity of the game and her comments are therefore more focused on the specific activity of killing: 'I'll kill you, no matter if it's the last thing I do', 'Well I'm just killing everybody. Whoa. Cool, I'm just killing everybody', 'I love killing people' [accompanied by a sniggering laugh], 'I want to kill someone. No offence to everyone' - a masculinised position. What I am suggesting here is that the successful game player is required to take up a visibly masculine subject position in terms of stereotypical performances of gender. (As Bella says at one point, 'I can do whatever I want. I'm a grown man now, mama.' She follows this by saying, 'I'm talking to me mama' in an affected/exaggerated masculine voice.)

A feminine position/performance must therefore disavow these inscriptions and emphasise their other or lack, such as occurs with Rosie's position of helplessness, fear, failure, self-depreciation and fits of giggling. Bella does not compete with Jo's social position of power within the 


\section{Is it really the case that the technology cannot be utilised in ways that are equally engaging to girls and equally supportive of their identity work, and so help with their learning?}

group, but competes with her character within the game. This allows for some power play that is legitimised by the activity of the game but not obvious or confrontational within the social group. Again, the group looks cohesive, democratic and friendly. The negotiations about who will play which characters is not tense or cause for argument, though negotiations do seem to be subtly mediated by Jo.

Rosie's performance during the group game is markedly different from that when she is playing in a pair with Bella. I account for this in at least two ways. First, she takes up different positions as a player and observer, more feminised when playing, and in the group she is always a player. Second, she is friends with Jo and I suspect she takes up a more exaggerated feminine position around Jo's performance of authority. Rosie giggles more, sucks her thumb and generally works harder to assert her fear and failure: 'I'm innocent', 'My enemy's myself', 'I'm dead, see what you do when you hurt people? They cry [giggles]', 'Don't hurt me please', 'I'm an idiot'. Completely absent from this episode is the type of power play that could be seen between Rosie and Bella in other exchanges. Jo positions herself as winner and Rosie is positioned by Bella as loser. However, careful scrutiny and insistence on Bella's part reveals that Rosie is actually second and Gaby third, leaving Jo in fourth place and Bella in first. Jo is resistant to being fourth and Bella clearly establishes her position as first. Interestingly, whilst Bella positions herself as winner and cannot believe it when she has lost ('How can that be?', 'I damn well came fourth'), Rosie positions herself as loser and cannot believe it when she is not ('Me? No I didn't ... I never win').

In this paper I have been exploring the position the girl players take up as game playing subjects and how this is reflected in the way they play the game; their position in relation to fighting, killing and winning; and the way they relate to other players, especially in terms of relations of power. I argue that the successful player and manager of the technology of the video game is a masculine subject and that this subject position is more available to some girls than others. I also argue that it requires complex, covert negotiations of power that position girls ambivalently, in the sense that they seem to struggle for power whilst appearing not to. Girls are also positioned ambivalently in terms of taking up a masculine position in one context, game playing, and adopting a feminine position in another, the interview, where fighting and winning are disavowed and the cuteness (and other appropriately feminine inscriptions) of characters are emphasised. I suggest that Jo and Bella are more mobile subjects, able to take up a masculine position in the context of the game, whilst Rosie, embedded in a stable performance of femininity, is less mobile across contexts. What is of interest here is the self-management strategies that the girls mobilise to produce (and re-produce) themselves as girls around this new textual practice.

\section{And what of pleasure?}

In relation to the complexity of self management tasks the girls have to accomplish, I want to explore the equally contradictory site of pleasure. We have seen that Bella and Rosie gain considerable pleasure from winning and killing, in a way not unlike that of the boys. There is pleasure then for girls in mastery. They can take up a masculine position, though not without having to almost simultaneously take up a feminine one as well. We saw that Rosie liked to display an exaggerated squeamishness, thus taking a vicarious pleasure in others doing the killing while saying she is afraid. As we know from horror movies, we can take great pleasure in squeamishness, watching the horror through our hands (Kristeva 1982, Clover 1992). What is the fascination with horror? What is the vicarious pleasure in violence? Is there any mileage in attempting to understand how Rosie manages to take pleasure in killing while operating as though she had nothing to do with it? All those fluffy cuddly creatures are of course so well satirised in the boiling of the family bunny by the abandoned woman in Fatal Attraction. Just as the Glen Close character seeks her revenge with a murderous fury, murdering too the sweet and acquiescing part of herself, so Rosie reveals that the violent must be kept in check to produce femininity, while for boys its opposite is the case, as the exaggerated denials of any interest in the game of Barbie make clear. The work of performing masculinity and femininity is also psychic work, the work Freud talks of so clearly (Rose 1983). It is also about the complexities of positions of power. The power of the mother over the child/man, the power of the femme fatale, the power of 
the pleasure in mastery, of omnipotent control, of winning and killing. The performance of femininity or masculinity requires social and psychic work in order to embody a position which is a necessary fiction in that it is the central constituent of the management and regulation of femininity and masculinity. So, what seems like power is in Foucault's sense (Foucault 1977) deeply compromised, because it is the way in which we are managed and regulated as autonomous citizens in apparent control of ourselves and our lives. I have argued that video games are sites in which masculinity is produced through a number of techniques and practices of self-management. I have argued that the task of femininity is different and that this makes the playing of games a complex self-management task for girls. We have seen how a number of girls take up different and shifting positions in relation to this. If the discursive work is also psychic work, then girls have to deal with an almost impossible task of holding together masculine and feminine positions. I suggest that this approach might be useful not only in relation to thinking about video games but also about debates about women and new technologies more generally.

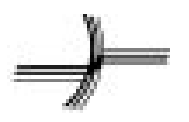

\section{REFERENCES}

Cassell, J. \& Jenkins, H. (1998) From Barbie to Mortal Kombat._Cambridge, MA, MIT Press.

Clover, C. (1992) Men, Women and Chainsaws. London, British Film Institute.
Foucault, M. (1977) Discipline and Punish. Harmondsworth, Penguin.

Foucault, M. (1986) History of Sexuality, vol. 3, The Care of the Self. New York, Pantheon.

Kristeva, J. (1982) The Powers of Horror. New York, Columbia University Press.

Neale, S. (1983) 'Masculinity as spectacle'. Screen 24, 6: 26- 40 .

Poole, S. (2000) Trigger Happy: The Inner Life of Video Games. London, Fourth Estate.

Rose, J. (1983) 'Femininity and its discontents'. Feminist Review, 14: 78-91.

Walkerdine, V. (1998) Counting Girls Out. London, Falmer.

Walkerdine, V. (2002) 'Video games and childhood masculinity'. Paper presented at Crossroads in Cultural Studies Conference, Tampere, Finland.

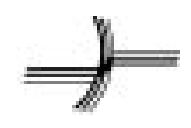

\section{BIOGRAPHICAL NOTE}

Valerie Walkerdine is Professor of Psychology in Cardiff School of Social Sciences, Cardiff University, UK. She is currently writing up her research on children and video games; the book will appear in 2005. 